Positive and negative intergroup contact and willingness to engage in intergroup interactions among high-status (Han) and low-status (Uyghur) group members in China: The moderating role of social dominance orientation

\author{
Changcheng Wang \\ Central Normal University of China, School of Psychology \\ Huang Fei \\ Central Normal University of China, School of Psychology
}

Sofia Stathi

University of Greenwich

Loris Vezzali

University of Modena and Reggio Emilia

Corresponding author: Changcheng Wang, School of Psychology, Central Normal University of China, Luoyu road 152, Hongshan district, Wuhan, China. Telephone number: 15151823025. E-mail: 15151823025@163.com

Fei Huang: School of Psychology, Central Normal University of China, Luoyu road 152, Hongshan district, Wuhan, China. Telephone number: 15151823025. E-mail: chengwang@mails.ccnu.edu.cn 


\title{
Positive and negative intergroup contact and willingness to engage in intergroup interactions among high-status (Han) and low-status (Uyghur) group members in China: The moderating role of social dominance orientation
}

\begin{abstract}
The present study investigated whether the associations of positive and negative intergroup contact with behavioral intentions (intentions to have contact with the outgroup in the future) are moderated by social dominance orientation (SDO), by considering the perspective of both high- and low-status group members in the context of China. Participants were 325 Han (high-status) and 373 Uyghur (low-status) members, who completed a self-report questionnaire. Results indicated that positive contact was associated with more positive behavioral intentions among high-SDO high-status group members, whereas SDO did not moderate the association between positive contact and behavioral intentions among low-status group members. In addition, negative contact was associated with lower behavioral intentions among high-SDO high-status group members, and among low-SDO low-status group members. This study suggests that attention should be placed simultaneously on positive and negative contact and on individual difference variables relevant to social ideologies, such as SDO.
\end{abstract}

Keywords: intergroup contact, positive contact, negative contact, social dominance orientation, contact behavioral intentions. 
Contact, as a situational variable, cannot always overcome the personal variable in prejudice. This is true whenever the inner strain within the person is too tense, too insistent, to permit him (sic) to profit from the structure of the outer situation.

Allport (1954, pp. 280-281)

Over more than sixty years of research, a plethora of studies have supported intergroup contact theory as one of the most promising theoretical approaches for the improvement of intergroup relations (Pettigrew \& Tropp, 2006, 2011). Recently, researchers have started to consider the interplay between contact and individual difference variables (Asbrock, Christ, Duckitt, \& Sibley, 2012; Turner, Dhont, Hewstone, Prestwich, \& Vonofakou, 2014; Vezzali, Turner, Capozza, \& Trifiletti, 2018), in line with the notion that situational and personality factors exert a joint influence on psychological outcomes and behavior (Kenrick \& Funder, 1988). A great deal of this research has focused on the role of social dominance orientation (SDO; Sidanius \& Pratto, 1999). In contrast to the initial theorization by Allport (1954) that positive contact would work best for low-prejudiced individuals, current research supports that contact effects are stronger among more prejudiced people, for example those with higher SDO (Hodson \& Dhont, 2015; Hodson, Turner, \& Choma, 2017).

It is important to acknowledge that although informative, the research that has examined the interplay between contact and individual differences has mainly been conducted in western countries with predominantly high-status groups. Therefore, we have yet no evidence that similar effects can generalize in eastern countries, or that similar patterns can emerge when considering low-status groups. In addition, evidence that negative contact interacts with SDO is limited (see Dhont \& Van Hiel, 2009). The present study is precisely aimed at addressing these two issues, by testing whether 
SDO moderates the relationship between both positive and negative contact and behavioral intentions in the Chinese context, among both high-status and low-status group members.

\section{Intergroup contact and social dominance orientation}

SDO is an individual difference variable indicating a preference (or not) for unequal relationships between groups in the society (Pratto, Sidanius, Stallworth, \& Malle, 1994; Sidanius \& Pratto, 1999). Duckitt (2001) defined SDO as a competition-driven motivation for group-based dominance. In a functional sense, SDO is an approach-oriented motivation dealing with the expression of power and hierarchy values (Navarrete, McDonald, Molina, \& Sidanius, 2010; Pratto et al., 1994). People who are high in SDO take advantage of hierarchy-enhancing ideologies, such as prejudice, to establish or maintain hierarchical rather than egalitarian relations between social groups (Sidanius \& Pratto, 1999). Several studies have indicated that individuals high in SDO typically exhibit negative outgroup attitudes (Dhont, Hodson, Costello, \& Macinnis, 2014; Kteily, Ho, \& Sidanius, 2012; Roets, Van Hiel, \& Dhont, 2012; Sibley, Robertson, \& Wilson, 2006) and general prejudice across a wide range of contexts (Duckitt \& Sibley, 2007; Zick et al., 2008; see also Pratto, Sidanius, \& Levin, 2006). Therefore, SDO represents a variable highly relevant to prejudice formation and one that may create a barrier between groups.

Allport's initial theorizing suggested that contact could be less effective among individuals most prone to prejudice, such as individuals high in SDO (see Pratto et al., 2006). In line with a Person $\times$ Situation approach (see Hodson $\&$ Dhont, 2015), in 
order to determine whether contact would work for individuals despite their level of SDO, the variable has been tested as a moderator of contact effects. Contradicting Allport's initial skepticism, results revealed that the association of positive contact with reduced prejudice is generally stronger among individuals characterized by higher levels of prejudice or related variables, such as SDO (Dhont \& Van Hiel, 2009; Hodson, 2008; Kauff, Schmid, Lolliot, Al Ramiah, \& Hewstone, 2016; Kteily, Hodson, Dhont, \& Ho, 2017; for evidence obtained with longitudinal methodologies, see Kauff, Schmid, et al., 2016, Study 3). For instance, Kteily et al. (2017) found that White-American adults' quality of contact with African-Americans was associated with reduced prejudice (on four out of five indicators) among individuals higher (vs. lower) in SDO (for reviews, see Hodson, 2011; Hodson et al., 2017).

Despite these findings, some studies did not find evidence that contact works better for high-SDO individuals. Schmid, Hewstone, Küpper, Zick, and Wagner (2014) examined a sample of host nationals from eight European countries, and found that contact with immigrants (a measure combining both direct and extended contact; Vezzali, Hewstone, Capozza, Giovannini, \& Wölfer, 2014; Wright, Aron, Mc-Laughlin-Volpe, \& Ropp, 1997; Zhou, Page-Gould, Aron, Moyer, \& Hewstone, 2018) was more strongly related to lower prejudice for individuals low (vs. high) in SDO. These results were replicated by Asbrock et al. (2012), who used large samples of German adult population (see also Asbrock, Gutenbrunner, \& Wagner, 2013, for evidence that SDO does not moderate the effects of imagined contact; Crisp \& Turner, 2012; Miles \& Crisp, 2014; Stathi, Crisp, Turner, West, \& Birtel, 2012). Meadows et 
al. (2017) found instead that SDO did not moderate the association between contact and anti-fat attitudes in a sample of over 3,500 medical students. However, as noted by Hodson and Dhont (2015), these large-scale studies used a restricted number of items to assess SDO, raising some concern regarding the measurement of the construct and the generalizability of the findings.

It should be noted that most studies investigating moderation of contact effects by SDO only focused on high-status group members' attitudes. One relevant exception is provided by Kauff, Schmid, et al. (2016, Study 5), who tested hypotheses by considering a sample of Asian adolescents in the UK. In this study, the association between contact with the White high-status group (i.e. cross-group friendship) and outgroup attitudes was not moderated by SDO.

Prior research on intergroup contact and its outcomes has focused mainly on positive contact, overlooking the role that negative contact plays on intergroup relations (Pettigrew, 2008). However, not only is negative contact associated with increased prejudice (Barlow et al., 2012), but its detrimental effects are comparably stronger than the beneficial effects of positive contact (Techakesari et al., 2015), an effect likely due to heightened membership salience during negative contact (Graf \& Paolini, 2017; Paolini, Harwood, \& Rubin, 2010). Surprisingly, to our knowledge only one study has tested whether negative contact interacts with SDO. Dhont and Van Hiel (2009, Study 2) found with a sample of 90 Belgians that the positive association between negative contact with immigrants and prejudice was only significant among high-SDO individuals. This study, however, focused on the 
attitudes of high-status group members and did not consider whether a similar pattern of findings would emerge for low-status group members.

\section{The present study}

A correlational study was conducted among Han (high-status group members) and Uyghur (low-status group members) in inland cities of China with the aim of examining whether the associations of positive and negative contact with prejudice are moderated by SDO. To assess prejudice, we used a measure of behavioral intentions to have contact with the outgroup in the future, as this variable should be a stronger predictor of actual behavior than outgroup attitudes (Fishbein \& Ajzen, 2010).

Han people represent the ethnic majority group in China and account for around $91.51 \%$ of the total population, while Uyghur people represent one of the 55 relevant ethnic minorities in China, constituting $0.76 \%$ of the population (J. Li, 2016). As a consequence of historical and contextual factors, status differences between Uyghur and Han people can be found in several domains, such as occupation, wealth, education, and living standards (Han \& States, 2010; Howell \& Fan, 2011; X. Li, 2012; Ma, 2011). The cultural differences between Uyghur and Han are predominantly reflected on three domains, language, religion, and customs (Yusup, 2013). While both ethnic groups have their own native language (Uyghur language for Uyghur, Chinese for Han), Uyghur also acquire the language of the other group at school. However, language constitutes a barrier to intergroup communication.

Furthermore, Han people do not have a dominant religion. Rather, they follow various 
religions, such as Buddhism, Taoism or atheism. In contrast, most of the Uyghur population practices Islam. With respect to customs, there are substantial differences relating to diet, reception, festivals, and funerals. Communication barriers caused by language and different religious beliefs and customs affect interactions between Uyghur and Han, creating negativity and conflict (X. Li, 2012). In fact, violent incidents between the two ethnic groups occurred in recent years, with severe consequences for individuals (Zhao \& Zhao, 2014). In addition, supported by foreign forces, ethnic separatism instigated divisions, created contradictions, and even lead individuals engage in criminal activities, with the consequences of intensifying conflict and causing harm to social stability, economic development and normal life of people in Xinjiang. In this context, testing the conditions that allow peaceful relations between the two ethnic groups, or those that prevent them, is of paramount importance.

Based on the reviewed literature, we predicted that among high-status group members positive contact would be associated with more positive behavioral intentions only among high-SDOs (H1). That is, given that positive contact should challenge perceptions of outgroup inferiority and disconfirm negative evaluations, individuals high in SDO (who typically discriminate outgroups that they perceive as legitimately 'inferior’; Levin, Sidanius, Rabinowitz, \& Federico, 1998; Pratto et al., 2006) should demonstrate stronger associations between contact and positive behavioral intentions. On the other hand, negative contact might increase the perceived legitimacy of the differential group status positions among high-SDO 
individuals. Given that these individuals are most likely to focus on group distinctions and pay attention to status hierarchies, they may 'use' negative contact to confirm their group superiority. Therefore, the association between negative contact and more negative behavioral intentions should be stronger among high-SDOs, compared to low-SDOs (H2).

For low-status group members, we also predicted that the association of positive and negative contact with behavioral intentions would be stronger for high-SDOs (vs. low-SDOs). We expected that high-SDO individuals from the low-status group would pay more attention to information (provided by contact) regarding groups at the top of the hierarchy; therefore, for these individuals, associations between contact and behavioral intentions are likely to depend on contact valence. In other words, we expected that the association of contact with behavioral intentions would be boosted by the level of SDO, such that positive contact should be associated with more positive (H3) and negative contact with less positive (H4) behavioral intentions among individuals high (but not low) in SDO.

\section{Method}

\section{Participants}

Participants were students from universities in inland cities in Northern China, Central China, Southern China and Southeastern China, where Han people represent the high-status group. Participants were distributed self-report questionnaires in dormitories or during classes by Uyghur and Han research assistants. Specifically, low-status participants were administered the questionnaire by researchers belonging 
to the low-status group (Uyghur), whereas high-status participants were administered the questionnaire by researchers belonging to the high-status group (Han). All participants were informed that the study aimed to investigate how Uyghur and Han people relate to each other and what their social attitudes are, and were briefed about ethics policies regarding anonymity, privacy and data protection. All participants took part in the study voluntarily and anonymously and were informed that they could stop their participation at any time. Upon completion, they were debriefed and given 10 RMB (Chinese currency).

We distributed a total of 769 questionnaires. After excluding participants with excessive missing variables (over 50\%), we obtained a final sample of 325 (191 females) high-status group members between 18 and 25 years $(M=20.63, S D=1.55)$, and of 373 (233 females) low-status group members between 17 and 25 years $(M=$ 21.74, $S D=1.74)$.

\section{Measures}

Intergroup contact. Positive contact was measured with the following items: "I cooperated with <outgroup> in some tasks," "<outgroup> greeted me actively," "I participated in (or organized) activities with <outgroup>," "I had delicious food or traveled with <outgroup>." Negative contact was assessed with the following items: "<outgroup $>$ responded indifferently to conversation initiated by myself," " $<$ outgroup $>$ insulted or threatened me," "I had trouble with $<$ outgroup $>$ in school activities or daily life," "< outgroup $>$ and I had divergent opinions on ethnic issues." The response scale ranged from 1 (never) to 5 (very often), with higher scores 
reflecting more positive and negative contact, respectively $\left(\alpha_{s}=.80\right.$ and .76 for positive and negative contact for high-status group members; $\alpha_{s}=.83$ and .79 for positive and negative contact for low-status group members).

SDO. SDO was measured using a short, four-item version of the SDO scale (Kauff, Schmid, et al., 2016). An example item is: "Inferior groups should stay in their place". The response scale ranged from 1 (strongly disagree) to 7 (strongly agree) $\left(\alpha_{\mathrm{s}}=.74\right.$ and .75 for high-status and low-status group members, respectively).

Behavioral intentions. Behavioral intentions were assessed with an adapted version of Ratcliff et al.'s (1999) behavioral intentions measure. Participants were asked to respond to 10 items on a 9-point scale, e.g., "How likely do you think it is that you would strike up a conversation with <outgroup>? $(1=$ not at all likely, $9=$ highly likely)," "How interested would you be in striking up a conversation with <outgroup>? $(1=$ not at all interested, $9=$ highly interested $)$." Higher scores indicate stronger desire to engage in interaction with the outgroup in the future $\left(\alpha_{\mathrm{s}}=.92\right.$ and .91 for high-status and low-status group members, respectively).

\section{Results}

Descriptive statistics and correlations are reported in Table 1.

To test the hypotheses, we conducted hierarchical regression analyses. In the first step, we included the three (centered) independent variables (positive and negative contact, SDO) and group membership (high-status coded 1, low-status coded -1). In the second step, we added the two-way interactions between positive and negative contact, respectively, with SDO and group. In the third step, we included the 
three-way interactions for both positive and negative contact. Results are presented in Table 2.

As can be noted, the three-way significant interaction emerged when considering both positive and negative contact. Simple slope analyses revealed that, for the high-status group, in line with $\mathrm{H} 1$, positive contact was positively related to behavioral intentions among high-SDOs $(+1 S D), b=.88, S E=.14, p<.001$, but not among low-SDOs $(-1 S D), b=.10, S E=.13, p=.439$ (Figure 1). Supporting H2, simple slope analysis revealed that negative contact was negatively related to behavioral intentions among high-SDOs $(+1 S D), b=-.47, S E=.18, p<.01$, but not among low-SDOs $(-1 S D), b=.24, S E=.21, p=.243$ (Figure 2).

With respect to low-status group members, in contrast with $\mathrm{H} 3$, simple slope analyses revealed that positive contact was positively associated with behavioral intentions both for high- and low-SDO individuals, $b \mathrm{~s}=.73$ and $.51, S E \mathrm{~s}=.12$ and $.12, p s<.001$. Also, in contrast with $\mathrm{H} 4$, simple slope analyses revealed that the negative association between negative contact and behavioral intentions was significant among low-SDOs, $b=-.58, S E=.13, p<.001$, but not among high-SDOs, $b=-.14, S E=.12, p=.234($ Figure 3$)$.

\section{Discussion}

The present study examined the association of positive and negative contact with behavioral intentions and their interaction with SDO among both high-status and low-status group members in the context of China. Importantly, we measured intentions to have contact with the outgroup in the future, a closer predictor of 
intergroup behavior than outgroup attitudes (Vezzali, Stathi, Giovannini, Capozza, \& Visintin, 2015) and a variable overlooked in research testing the combined effects of contact and SDO.

Results demonstrated that, predictably and in line with the literature (Graf \& Paolini, 2017), positive contact was associated with more positive behavioral intentions among both groups, whereas a negative association emerged between negative contact and behavioral intentions. More relevant to the present study, we found significant moderator effects by SDO.

With respect to the high-status group, results were consistent in most part with previous research (Hodson et al., 2017). In particular, we found that positive contact was associated with more positive behavioral intentions only among individuals higher in SDO. It is worth noting that, when positive contact was more frequent, high-SDOs displayed similar levels of contact intentions as low-SDOs (cf. Figure 1). It seems therefore that (positive) contact has the potential to eliminate differences between high- and low-SDOs, contributing this way to the improvement of intergroup relations.

In line with our theorizing, it is possible that for high-SDO individuals (who are likely to be the most prejudiced; Pratto et al., 2006) contact activated a process that led to perceptions that the lower status position of the outgroup is illegitimate, in turn fostering willingness for contact. This is in line with recent findings by Di Bernardo et al. (2018), who showed that high-status group members' positive contact with the low-status group was associated with more positive outgroup perceptions via 
increased illegitimacy of status distinctions. Similarly, Selvanathan, Techakesari, Tropp, and Barlow (2017) found that anger over injustice (therefore a construct conceptually associated with status illegitimacy) mediated the relationship between positive contact and collective action intentions among high-status group members. The present study advances these findings, showing that this effect may be more pronounced for individuals with higher SDO, namely those most likely to attribute legitimacy to the superior position of the high-status group.

There are however alternative explanations for this finding. For instance, high-SDOs from the high-status group may interpret positive contact as an indication that low-status group members are content with their lower position in the status hierarchy, and react with stronger intentions to meet them. This explanation would be consistent with system justification theory (Jost, Banaji, \& Nosek, 2004), since high-status group members with stronger tendencies to maintain the status quo (such as, high-SDOs) may want to 'use' positive contact as a way to justify the existing social system. Future studies should address these two competing explanations and shed light on why the effects of positive contact are enhanced by SDO. ${ }^{1}$

Results for negative contact among the high-status group replicated results from the single prior study (Dhont \& Van Hiel, 2009, Study 2), revealing that the association between negative contact and more negative behavioral intentions was only significant among high-SDOs. Possibly, negative contact confirmed negative expectations among high-SDO individuals, who used these experiences to legitimize their advantaged position and avoid contact with the outgroup (at the level of 
intentions). Negative contact may act as an attempt from low-status group members to challenge the status quo, therefore leading to more bias among high SDOs. Also, for high-SDOs, confirmation of negative expectations following negative contact possibly led to increased membership salience and outgroup prototypicality (Graf \& Paolini, 2017) and fostered generalization of (negative) outgroup attitudes (Brown \& Hewstone, 2005).

In contrast with predictions, but consistent with Kauff, Schmid, et al.'s (2016) findings, among low-status group members, the outcome of positive contact was not moderated by SDO. This finding may be due, at least in part, to a ceiling effect, given that the mean for positive contact was rather high, and the standard deviation rather low. However, moderation effects were obtained for negative contact, despite that the mean was even closer to the far end of the response scale, and the standard deviation was lower (cf. Table 1). It should be noted that contact was positively associated with behavioral intentions, and the absence of moderation indicates that this was true among participants both high or low in SDO. Individuals from low-status groups with high SDO may have ambivalent motivations, being driven toward favoring the ingroup or supporting a status hierarchy where they are the disadvantaged group (Jost et al., 2004; Pratto et al., 2006). Possibly, these individuals appraise positive contact differently from those lower in SDO. For instance, positive contact may foster legitimacy of the status hierarchy among high-SDOs (in turn promoting intentions to meet the legitimate high-status group members), or disconfirm negative stereotypes and foster psychological closeness among low-SDOs (which in turn should lead to 
greater willingness for contact). In other words, it is possible that SDO moderates the associations between positive contact and mediating variables among low-status group members, but the absence of potential mediators in the present study prevents us from testing empirically this possibility. Future research can examine this and provide evidence for other variables that explain the path to positive intergroup relations.

Also inconsistent with our predictions, the results showed that among low-status group members negative contact was associated with more negative behavioral intentions only among individuals low in SDO. Possibly, among low-SDOs negative interactions with the high-status group highlight status inequalities, thereby raising group barriers and reducing intentions to meet high-status group members. In contrast, low-status individuals high in SDO may be relatively unaffected by negative contact experiences with the high-status group, given that their social ideology supports the status hierarchy (and presumably, to an extent, members of higher-status groups). Note that high- and low-SDOs displayed similar levels of behavioral intentions when negative contact was more frequent (cf. Figure 3). Paralleling our observation above, negative contact may minimize differences between high- and low-SDOs, in this case fostering hostility between the two groups. As we stated above, however, the absence of potential mediators does not allow to test the processes underlying low-status group members' reaction to negative contact depending on their SDO level.

Recent research showed that positive contact can have unintended negative consequences, such as undermining the willingness to engage in actions for social 
change, both among high-status (Jackman \& Crane, 1986; but see Reimer et al., 2017; Selvanathan et al., 2017) and low-status group members (Becker, Wright, Lubensky, \& Zhou, 2013; Çakal, Hewstone, Schwär, \& Heath, 2011; Hayward, Tropp, Hornsey, \& Barlow, 2018; Saguy, Tausch, Dovidio, \& Pratto, 2009; Sengupta \& Sibley, 2013; Tropp, Hawi, Van Laar, \& Levin, 2012; but see Kauff, Green, Schmid, Hewstone, \& Christ, 2016; for reviews, see McKeown \& Taylor, 2017; Saguy, Shchory-Eyal, Hasan-Aslih, Sobol, \& Dovidio, 2017). There is also initial evidence that negative contact is associated with greater collective action intentions (Hayward et al., 2018). Negative contact may however have differential effects depending on group membership, and be associated with greater collective action intentions among low-status group members, but with lower collective action intentions on behalf of the low-status group among high-status group members (Reimer et al., 2017).

Our results, although not examining collective action, provide some indications that may be relevant to the contact and collective action research. Among high-status group members, the fact that associations between positive contact and behavioral intentions only emerged among high-SDO individuals, who are more interested in maintaining status differences, suggests that positive contact can influence precisely those individuals that are more likely to oppose resistance to intergroup equality. The fact, however, that high-SDO individuals were also those reacting with greater prejudice in response to negative contact suggests that negative contact is likely to boost not only lower intentions to side with the low-status group, but also greater intentions to actively oppose equality practices among those who are more willing to 
maintain a stable status hierarchy.

Among low-status individuals, although we did not find significant moderation of positive contact by SDO on behavioral intentions, it is still possible that positive contact is associated with greater awareness of injustices among high-SDOs, who are likely to pay more attention to status distinctions. Our findings provide indications that low-SDOs may respond to negative contact with increased prejudice and, we speculate, greater intentions to address status inequalities. This outcome may be less strong among high-SDOs, who are more supportive of status inequality and, therefore, may be less sensitive to negative contact as a factor motivating the reduction of this inequality. Since these are only speculations, we believe there is a need of research investigating both positive and negative contact and collective action, taking into account SDO, which is one of the most relevant variables when looking into preferences for status inequality.

Kauff, Schmid, et al. (2016) tested the moderation of contact by SDO also taking into account the underlying processes. In particular, they identified ingroup distancing as a key variable; results showed that among high-status (but not low-status) group members positive contact (i.e. cross-group friendships) was associated with more positive outgroup attitudes via ingroup distancing among those higher in SDO. The inclusion of underlying processes, and additional outcome variables such as collective action intentions (see above) would allow to better disentangle the effects of positive and negative contact from the perspective of the high- or low-status groups.

We believe that this study has several strengths. First, it examines whether 
contact effects are moderated by SDO in a novel intergroup context. To the extent that much psychological research uses WEIRD participants (from western, educated, industrialized, rich and democratic countries) to explore general models (Henrich, Heine, \& Norenzayan, 2010), testing (and extending) models by considering less frequently investigated contexts is important. The reason being, models that generalize across western and eastern societies yield confidence in their tenets and can provide useful tools for understanding complex social issues.

Second, our study tests for the first time moderation by SDO for both positive and negative contact, and it takes into account both high-status and low-status group members. In addition, whereas only one previous study tested whether SDO moderates the associations of negative contact with outcome variables among high-status group members (Dhont \& Van Hiel, 2009), this is the first test of moderation of associations between negative contact and outcome variables by SDO among low-status group members. Since research examining moderation of contact effects has been conducted predominantly with high-status groups and considering positive contact, by focusing on both negative and positive contact and considering the perspectives of both high- and low- status groups, our results extend current knowledge and provide important future research avenues for intergroup relations scholars. Third, previous research examining SDO as moderator focused on outgroup attitudes. Our research extends previous findings by considering behavioral intentions to have contact with the outgroup in the future, a variable that is a stronger predictor of cross-group behavior than outgroup attitudes (Vezzali et al., 2015). To the extent 
that the impact of contact on attitudes or behavior (or a proxy of it such as behavioral intentions) may differ, we believe it is important that research examines a wide range of outcome variables with a specific focus on variables that are more likely to affect actual behavior.

This study helps addressing mixed findings in literature, by testing hypotheses on both high- and low-status groups considering both positive and negative contact. The results support previous evidence that positive contact is more influential for high-SDO individuals from high-status groups (Hodson et al., 2017) but also examine a fuller picture, showing that SDO also enhances the association of negative contact with behavioral intentions. Considering that negative contact is generally more influential than positive contact (Graf \& Paolini, 2017), optimistic conclusions by contact scholars regarding the positive effects of positive contact for high-SDOs should be toned down. Although in our study negative contact did not exacerbate high-SDOs low-status group members' negative orientation, results suggested that it may worsen the relatively positive orientation of low-SDOs low-status group members. This can arguably lead to homogeneous negative orientations regardless of SDO levels among the low-status group. There is therefore a need to consider the joint influence of positive and negative contact between groups at different levels of the status hierarchy, and understand how to buffer the negative effects of negative contact across SDO levels while at the same time maintaining the positive effects of positive contact.

We believe this study has important practical implications. Given the detrimental 
effect of negative contact among individuals from high-status groups who are also high in SDO, it is vital to create optimal contact conditions (Allport, 1954) that maximize the effectiveness of positive contact. Category salience is presumably higher for high-status group members high in SDO, given the importance they attribute to categorical distinctions and superior position of one group over other groups. Since these were the individuals mostly affected by contact, we argue that contact interventions should bring attention to status differences. Heightened attention to group differences should then allow generalization of outgroup attitudes (Brown \& Hewstone, 2005), independently of the level of SDO. Moreover, since individuals do experience negative contact, and this negative contact has negative consequences on outgroup attitudes (Graf \& Paolini, 2017), a result also confirmed in this study, contact interventions should acknowledge it. When using contact strategies to reduce prejudice, people can be aware that negative contact experiences occur, but that this should not undermine the importance of positive contact experiences. Awareness of the occurrence and impact of negative contact may also desensitize individuals from negative contact experiences, and allow them to value positive contact experiences to an even greater extent (Birtel \& Crisp, 2012).

Despite these meaningful findings, we acknowledge that the cross-sectional methodology of our study does not allow us to make causal claims. Moreover, we did not consider other individual difference variables that may qualify the effects of positive and negative contact (Hodson \& Dhont, 2015). As noted above, we also did not consider additional outcome variables for which results may differ (e.g., collective 
action) or potentially relevant underlying processes. Finally, our conclusions on the moderating role of SDO are somewhat limited by the use of a shorter version of the SDO scale.

In conclusion, the present findings support the role of both positive and negative contact among both high- and low- status groups in shaping intentions to have contact in the future, and address concerns that individuals high in social dominance may be resistant to attitude change (Esses \& Hodson, 2006). Our study suggests that contact research should take into consideration individual difference variables, which can influence how people appraise the contact situation, be it positive or negative, and determine how they approach future intergroup encounters. 


\section{Footnotes}

1. We thank an anonymous Reviewer for suggesting this explanation. 


\section{References}

Allport, G. (1954). The nature of prejudice. Reading, MA: Addison-Wesley.

Asbrock, F., Christ, O., Duckitt, J., \& Sibley, C. G. (2012). Differential effects of intergroup contact for authoritarians and social dominators: A dual process model perspective. Personality and Social Psychology Bulletin, 38, 477-490. doi:10.1177/0146167211429747

Asbrock, F., Gutenbrunner, L., \& Wagner, U. (2013). Unwilling, but not unaffected Imagined contact effects for authoritarians and social dominators. European Journal of Social Psychology, 43, 404-412. doi:10.1002/ejsp.1956

Barlow, F. K., Paolini, S., Pedersen, A., Hornsey, M. J., Radke, H. R., Harwood, J., ... \& Sibley, C. G. (2012). The contact caveat: Negative contact predicts increased prejudice more than positive contact predicts reduced prejudice. Personality and Social Psychology Bulletin, 38, 1629-1643. doi:10.1177/0146167212457953

Becker, J. C., Wright, S. C., Lubensky, M. E., \& Zhou, S. (2013). Friend or ally: Whether cross-group contact undermines collective action depends on what advantaged group members say (or don't say). Personality and Social Psychology Bulletin, 39, 442-455. doi:10.1177/0146167213477155

Birtel, M. D., \& Crisp, R. J. (2012). “Treating” prejudice: An exposure-therapy approach to reducing negative reactions toward stigmatized groups. Psychological Science, 23, 1379-1386. doi:10.1177/0956797612443838

Brown, R., \& Hewstone, M. (2005). An integrative theory of intergroup contact. Advances in Experimental Social Psychology, 37, 255-343. doi:10.1016/S00652 
601(05)37005-5

Çakal, H., Hewstone, M., Schwär, G., \& Heath, A. (2011). An investigation of the social identity model of collective action and the 'sedative'effect of intergroup contact among Black and White students in South Africa. British Journal of Social Psychology, 50, 606-627. doi:10.1111/j.2044-8309.2011.02075.x

Crisp, R. J., \& Turner, R. N. (2012). The imagined contact hypothesis. Advances in Experimental Social Psychology, 46, 125-182. doi:10.1016/B978-0-12-394281-4.00003-9https://s100.copyright.com/AppDispatchSe rvlet?publisherName $=$ ELS\&contentID $=$ B9780123942814000039\&orderBeanReset $=$ true

Dhont, K., Hodson, G., Costello, K., \& Macinnis, C. C. (2014). Social dominance orientation connects prejudicial human-human and human-animal relations. Personality \& Individual Differences, 61-62, 105-108. doi:10.1016/j.paid.2013.12.020

Dhont, K., \& Van Hiel, A. (2009). We must not be enemies: Interracial contact and the reduction of prejudice among authoritarians. Personality and Individual Differences, 46, 172-177. doi:10.1016/j.paid.2008.09.022

Di Bernardo, G. A., Vezzali, L., Stathi, S., McKeown, S., Capozza, D., \& Dixon, J. (2018). Fostering social change among advantaged and disadvantaged group members: Integrating intergroup contact and social identity perspectives on collective action. Under review.

Duckitt, J. (2001). A dual-process cognitive-motivational theory of ideology and prejudice. Advances in Experimental Social Psychology, 33, 41-113. 
doi:10.1016/S0065-2601(01)80004-6

Duckitt, J., \& Sibley, C. G. (2007). Right-wing authoritarianism, social dominance orientation and the dimensions of generalized prejudice. European Journal of Personality, 21, 113-130. doi:10.1002/per.614

Esses, V. M., \& Hodson, G. (2006). The role of lay perceptions of ethnic prejudice in the maintenance and perpetuation of ethnic bias. Journal of Social Issues, 62, 453-468. doi:10.1111/j.1540-4560.2006.00468.x

Fishbein, M., \& Ajzen, I. (2010). Predicting and changing behavior: The reasoned action approach. New York, NY: Psychology Press.

Graf, S., \& Paolini, S. (2017). Investigating positive and negative intergroup contact. In L. Vezzali \& S. Stathi (Eds.), Intergroup contact theory: Recent developments and future directions (pp. 92-113). New York, NY: Routledge.

Han, E., \& States, U. (2010). Boundaries, discrimination, and interethnic conflict in Xinjiang, China. International Journal of Conflict and Violence, 4, 244-256. doi:10.4119/UNIBI/ijcv.77

Hayward, L. E., Tropp, L. R., Hornsey, M. J., \& Barlow, F. K. (2018). How negative contact and positive contact with Whites predict collective action among racial and ethnic minorities. British Journal of Social Psychology, 57, 1-20. doi:10.1111/bjso.12220

Henrich, J., Heine, S.J., \& Norenzayan, A. (2010). Most people are not WEIRD. Nature, 466, 29. doi:10.1038/466029a

Hodson, G. (2008). Interracial prison contact: The pros for (socially dominant) cons. 
British Journal of Social Psychology, 47, 325-351.

doi:10.1348/014466607X231109

Hodson, G. (2011). Do ideologically intolerant people benefit from intergroup contact?

Current Directions in Psychological Science, 20, 154-159.

doi:10.1177/0963721411409025

Hodson, G., \& Dhont, K. (2015). The person-based nature of prejudice: Individual difference predictors of intergroup negativity. European Review of Social Psychology, 26, 1-42. doi:10.1080/10463283.2015.1070018

Hodson, G., Turner, R. N., \& Choma, B. L. (2017). Individual differences in intergroup contact propensity and prejudice reduction. In L. Vezzali \& S. Stathi (Eds.), Intergroup contact theory: Recent developments and future directions (pp. 8-30). Abingdon, UK: Routledge.

Howell, A., \& Fan, C. (2011). Migration and inequality in Xinjiang: A survey of Han and Uyghur migrants in Urumqi. Eurasian Geography and Economics, 52, 119-139. doi:10.2747/1539-7216.52.1.119

Jackman, M. R., \& Crane, M. (1986). "Some of my best friends are black...": Interracial Friendship and Whites' Racial Attitudes. Public Opinion Quarterly, 50, 459-486. doi:10.1086/268998

Jost, J. T., Banaji, M. R., \& Nosek, B. A. (2004). A decade of system justification theory: Accumulated evidence of conscious and unconscious bolstering of the status quo. Political Psychology, 25, 881-919.

doi:10.1111/j.1467-9221.2004.00402.x 
Kauff, M., Green, E. G. T., Schmid, K., Hewstone, M., \& Christ, O. (2016). Effects of majority members' positive intergroup contact on minority members' support for ingroup rights: Mobilizing or demobilizing effects? European Journal of Social Psychology, 46, 833-839. doi:10.1002/ejsp.2194

Kauff, M., Schmid, K., Lolliot, S., Al Ramiah, A., \& Hewstone, M. (2016). Intergroup contact effects via ingroup distancing among majority and minority groups:

Moderation by social dominance orientation. Plos One, 11, 1-28.

doi:10.1371/journal.pone.0146895

Kenrick, D. T., \& Funder, D. C. (1988). Profiting from controversy: Lessons from the person-situation debate. American Psychologist, 43, 23-34.

doi:10.1037//0003066X.43.1.23

Kteily, N., Ho, A. K., \& Sidanius, J. (2012). Hierarchy in the mind: The predictive power of social dominance orientation across social contexts and domains. Journal of Experimental Social Psychology, 48, 543-549. doi:10.1016/j.jesp.2011.11.007

Kteily, N. S., Hodson, G., Dhont, K., \& Ho, A. K. (2017). Predisposed to prejudice but responsive to intergroup contact? Testing the unique benefits of intergroup contact across different types of individual differences. Group Processes and Intergroup Relations. Advance online publication. doi:10.1177/1368430217716750

Levin, S., Sidanius, J., Rabinowitz, J. L., \& Federico, C. (1998). Ethnic identity, legitimizing ideologies, and social status: A matter of ideological asymmetry. Political Psychology, 19, 373-404. doi:10.1111/0162-895X.00109

Li, J. (2016). The population development and changes of Uyghur on the perspective 
of ethnic development (2000-2010). Qinghai Journal of Ethnology, 27, 72-76.

Li, X. (2012). On the trend of ethnic relations in Xinjiang and its influencing factors. Journal of the Second Northwest University for Nationalities, 103, 40-48.

Ma, X. (2011). Investigation interethnic relations of Uyghur and Han in Hetian, Xinjiang. Social Sciences in Xinjiang, 6, 64-69.

McKeown, S., \& Dixon, J. (2017). The "contact hypothesis": Critical reflections and future directions. Social and Personality Psychology Compass, 11, e12295. doi:10.1111/spc3.12295

Meadows, A., Higgs, S., Burke, S. E., Dovidio, J. F., van Ryn, M., \& Phelan, S. M. (2017). Social dominance orientation, dispositional empathy, and need for cognitive closure moderate the impact of empathy-skills training, but not patient contact, on medical students' negative attitudes toward higher-weight patients. Frontiers in Psychology, 8, 504. doi:10.3389/fpsyg.2017.00504

Miles, E., \& Crisp, R. J. (2014). A meta-analytic test of the imagined contact hypothesis. Group processes and Intergroup Relations, 17, 3-26. doi:10.1177/1368430213510573

Navarrete, C. D., McDonald, M. M., Molina, L. E., \& Sidanius. J. (2010). Prejudice at the nexus of race and gender: An outgroup male target hypothesis. Journal of personality and social psychology, 98, 933-945. doi:10.1037/a0017931

Paolini, S., Harwood, J., \& Rubin, M. (2010). Negative intergroup contact makes group memberships salient: Explaining why intergroup conflict endures. Personality and Social Psychology Bulletin, 36, 1723-1738. 
doi:10.1177/0146167210388667

Pettigrew, T. F. (2008). Future directions for intergroup contact theory and research. International Journal of Intercultural Relations, 32, 187-199. doi:10.1016/j.ijintrel.2007.12.002

Pettigrew, T. F., \& Tropp, L. (2006). A meta-analytic test of intergroup contact theory. Journal of Personality and Social Psychology, 90, 751-783. doi:10.1037/00223514.90.5.751

Pettigrew, T. F., \& Tropp, L. R. (2011). When groups meet: The dynamics of intergroup contact. New York, NY: Psychology Press.

Pratto, F., Sidanius, J., \& Levin, S. (2006). Social dominance theory and the dynamics of intergroup relations: Taking stock and looking forward. European review of Social Psychology, 17, 271-320.

Pratto, F., Sidanius, J., Stallworth, L. M., \& Malle, B. M. (1994). Social dominance orientation: A personality variable predicting social and political attitudes. Journal of Personality and Social Psychology, 67, 741-763. doi:10.1037//00223514.67.4.741

Ratcliff, C. D., Czuchry, M., Scarberry, N. C., Thomas, J. C., Dansereau, D. F., \& Lord, C. G. (1999). Effects of directed thinking on intentions to engage in beneficial activities: Actions versus reasons. Journal of Applied Social Psychology, 29, 994-1009. doi:10.1111/j.1559-1816.1999.tb00136.x

Reimer, N. K., Becker, J. C., Benz, A., Christ, O., Dhont, K., Klocke, U., ... \& Hewstone, M. (2017). Intergroup contact and social change: Implications of 
negative and positive contact for collective action in advantaged and disadvantaged groups. Personality and Social Psychology Bulletin, 43, 121-136. doi:10.1177/0146167216676478

Roets, A., Van Hiel, A., \& Dhont, K. (2012). Is sexism a gender issue? A motivated social cognition perspective on men's and women's sexist attitudes toward own and other gender. European Journal of Personality, 26, 350-359. doi:10.1002/per.843

Saguy, T., Shchory-Eyal, N., Hasan-Aslih, S., Sobol, D., \& Dovidio, J. F. (2017). The irony of harmony: Past and new developments. In L. Vezzali \& S. Stathi (Eds.), Intergroup contact theory: Recent developments and future directions (pp. 53-71). Abingdon, UK: Routledge.

Saguy, T., Tausch, N., Dovidio, J. F., \& Pratto, F. (2009). The irony of harmony: Intergroup contact can produce false expectations for equality. Psychological Science, 20, 114-121. doi:10.1111/j.1467-9280.2008.02261.x

Schmid, K., Hewstone, M., Küpper, B., Zick, A., \& Wagner, U. (2014). Secondary transfer effects of intergroup contact: A cross-national comparison in Europe. Social Psychology Quarterly, 75, 28-51. doi:10.1177/0190272511430235

Selvanathan, H. P., Techakesari, P., Tropp, L. R., \& Barlow, F. K. (2017). Whites for racial justice: How contact with Black Americans predicts support for collective action among White Americans. Group Processes and Intergroup Relations. Advance online publication. doi:10.1177/1368430217690908

Sengupta, N. K., \& Sibley, C. G. (2013). Perpetuating one's own disadvantage: 
Intergroup contact enables the ideological legitimation of inequality. Personality and Social Psychology Bulletin, 39, 1391-1403. doi:10.1177/0146167213497593

Sibley, C. G., Robertson, A., \& Wilson, M. S. (2006). Social dominance orientation and right-wing authoritarianism: Additive and interactive effects. Political Psychology, 27, 755-768. doi:10.1111/j.1467-9221.2006.00531.x

Sidanius, J., \& Pratto, F. (1999). Social dominance: An intergroup theory of social hierarchy and oppression. Cambridge, MA: Cambridge University Press.

Stathi, S., Crisp, R. J., Turner, R. N., West, K., \& Birtel, M. (2012). Using mental imagery to promote positive intergroup relations. In D. W. Russel \& C. A. Russel (Eds.), The psychology of prejudice: Interdisciplinary perspectives on contemporary issues (pp. 235-250). Nova publishers.

Techakesari, P., Barlow, F. K., Hornsey, M. J., Sung, B., Thai, M., \& Chak, J. L. Y. (2015). An investigation of positive and negative contact as predictors of intergroup attitudes in the United States, Hongkong, and Thailand. Journal of Cross-Cultural Psychology, 46, 454-468. doi:10.1177/0022022115570313

Tropp, L. R., Hawi, D. R., Van Laar, C., \& Levin, S. (2012). Cross-ethnic friendships, perceived discrimination, and their effects on ethnic activism over time: A longitudinal investigation of three ethnic minority groups. British Journal of Social Psychology, 51, 257-272. doi:10.1111/j.2044-8309.2011.02050.x

Turner, R. N., Dhont, K., Hewstone, M., Prestwich, A., \& Vonofakou, C. (2014). The role of personality factors in the reduction of intergroup anxiety and amelioration of outgroup attitudes via intergroup contact. European Journal of Personality, 28, 
180-192. doi:10.1002/per.1927

Vezzali, L., Hewstone, M., Capozza, D., Giovannini, D., \& Wölfer, R. (2014).

Improving intergroup relations with extended and vicarious forms of indirect contact. European Review of Social Psychology, 25, 314-389.

doi:10.1080/10463283.2014.982948

Vezzali, L., Stathi, S., Giovannini, D., Capozza, D., \& Visintin, E. P. (2015). “And the best essay is...": Extended contact and cross-group friendships at school. British Journal of Social Psychology, 54, 601-615. doi:10.1111/bjso.12110

Vezzali, L., Turner, R. N., Capozza, D., \& Trifiletti, E. (2018). Does intergroup contact predict personality? A longitudinal study on the bidirectional relationship between intergroup contact and personality traits. European Journal of Social Psychology, 48, 159-173. doi:10.1002/ejsp.2313

Wright, S. C., Aron, A., McLaughlin-Volpe, T., \& Ropp, S. A (1997). The extended contact effect: Knowledge of cross-group friendships and prejudice. Journal of Personality and Social Psychology, 73, 73-90. doi:10.1037/0022-3514.73.1.73

Zhao, G. F., \& Zhao, G. L., (2014). On adjustment and control of socio-psychological atmosphere after the occurrence of violent terrorist event. Journal of Shandong Police College, 26, 87-94.

Zhou, S., Page-Gould, E., Aron, A., Moyer, A., \& Hewstone, M. (2018). The extended contact hypothesis: A meta-analysis on 20 years of research. Personality and Social Psychology Review. Advance online publication. doi:10.1177/1088868318762647 
Zick, A., Wolf, C., Küpper, B., Davidov, E., Schmidt, P., \& Heitmeyer, W. (2008). The syndrome of group-focused enmity: The interrelation of prejudices tested with multiple cross-sectional and panel data. Journal of Social Issues, 64, 363-383. doi:10.1111/j.1540-4560.2008.00566.x 
Table 1. Descriptive statistics and correlations among variables.

\begin{tabular}{lcccccc}
\hline Variables & 1 & 2 & 3 & 4 & $M$ & $S D$ \\
\hline 1. Positive contact & - & -.09 & $-.16^{* *}$ & $.35^{* * *}$ & 4.08 & 0.76 \\
2. Negative contact & -.11 & - & $.12^{*}$ & $-.21^{* * *}$ & 1.66 & 0.73 \\
3. SDO & $-.19^{* * *}$ & $.17^{* *}$ & - & $-.15^{* *}$ & 2.28 & 1.16 \\
4. Behavioral intentions & $.34^{* * *}$ & $-.14^{*}$ & $-.43^{* * *}$ & - & 6.54 & 1.50 \\
$\quad M$ & 2.59 & 1.45 & 2.38 & 5.44 & & \\
$\quad S D$ & 0.89 & 0.59 & 0.87 & 1.51 & & \\
\hline
\end{tabular}

Note. The response scale ranged from 1 to 5 for positive and negative contact, from 1 to 7 for SDO, from 1 to 9 for behavioral intentions. Correlations for majority members are reported below the diagonal; correlations for minority members are reported above the diagonal. ${ }^{*} p<.05 .{ }^{* *} p<.01 .{ }^{* * *} p \leq .001$. 
Table 2. Moderation analyses of the effect of contact and SDO on behavioral intentions.

\begin{tabular}{|c|c|c|c|c|c|c|}
\hline & First step & $95 \% C I$ & Second step & $95 \% C I$ & Third step & $95 \% C I$ \\
\hline Positive contact & $.54^{* * *}(.06)$ & {$[.41, .67]$} & $.53^{* * *}(.06)$ & {$[.40, .65]$} & $.56^{* * *}(.06)$ & {$[.43, .68]$} \\
\hline Negative contact & $-.28^{* * * *}(.08)$ & {$[-.44,-.12]$} & $-.25^{* *}(.08)$ & {$[-.41,-.09]$} & $-.24^{* *}(.08)$ & {$[-.40,-.08]$} \\
\hline SDO & $-.28^{* * *}(.05)$ & {$[-.38,-.17]$} & $-.36^{* * *}(.05)$ & {$[-.46,-.25]$} & $-.27^{* * *}(.07)$ & {$[-.42,-.13]$} \\
\hline Group & $-.16 *(.07)$ & {$[-30,-.02]$} & $-.16^{*}(.07)$ & {$[-.30,-.03]$} & $-.10(.08)$ & {$[-.24, .04]$} \\
\hline Positive contact $\times$ SDO & & & $.21^{* * *}(.06)$ & {$[.09, .32]$} & $.24^{* * *}(.06)$ & {$[.12, .36]$} \\
\hline Negative contact $\times \mathrm{SDO}$ & & & $.09(.07)$ & {$[-.04, .22]$} & $-.07(.08)$ & {$[-.22, .09]$} \\
\hline Positive contact $\times$ Group & & & $-.08(.06)$ & {$[-.20, .05]$} & $-.38^{*}(.16)$ & {$[-.69,-.08]$} \\
\hline Negative contact $\times$ Group & & & $.10(.08)$ & {$[-.06, .25]$} & $.77^{* * *}(.21)$ & {$[.36,1.18]$} \\
\hline $\mathrm{SDO} \times$ Group & & & $-.09(.07)$ & {$[-.24, .05]$} & $-.05(.07)$ & {$[-.19, .10]$} \\
\hline Positive contact $\times$ SDO $\times$ Group & & & & & $.14^{*}(.06)$ & {$[.02, .26]$} \\
\hline Negative contact $\times$ SDO $\times$ Group & & & & & $-.28^{* * *}(.08)$ & {$[-.43,-.12]$} \\
\hline$R^{2}$ & .27 & & .31 & & .33 & \\
\hline$F$ & $63.77^{* * *}$ & & $34.03^{* * *}$ & & $30.10^{* * *}$ & \\
\hline$d f$ & $(4,693)$ & & $(9,688)$ & & $(11,686)$ & \\
\hline$F_{\text {change }}$ & & & $7.75^{* * *}$ & & $8.90^{* * *}$ & \\
\hline$d f$ & & & $(5,688)$ & & $(2,686)$ & \\
\hline
\end{tabular}

Note. For the variable "Group", 1 indicated high-status and -1 indicated low-status.

${ }^{*} p<.05 .{ }^{* *} p<.01 .{ }^{* * *} p \leq .001$. 


\section{Figure captions}

Figure 1. Associations between positive contact and behavioral intentions as a function of SDO (calculated at $+1 S D$ or $-1 S D$ ) among high-status group members.

Figure 2. Associations between negative contact and behavioral intentions as a function of SDO (calculated at $+1 S D$ or $-1 S D$ ) among high-status group members.

Figure 3. Associations between negative contact and behavioral intentions as a function of SDO (calculated at $+1 S D$ or $-1 S D$ ) among low-status group members. 
Figure 1

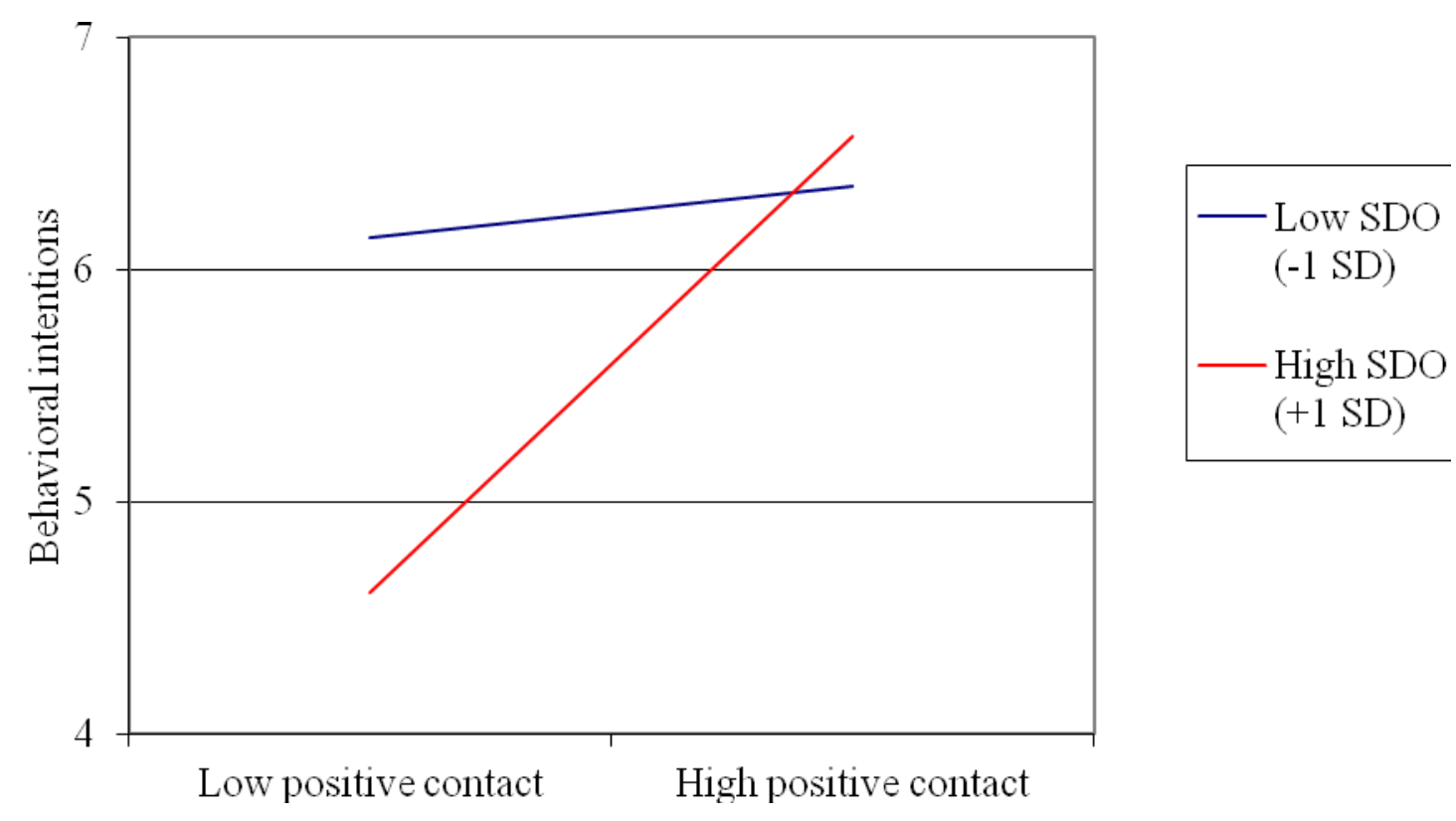

Figure 2 


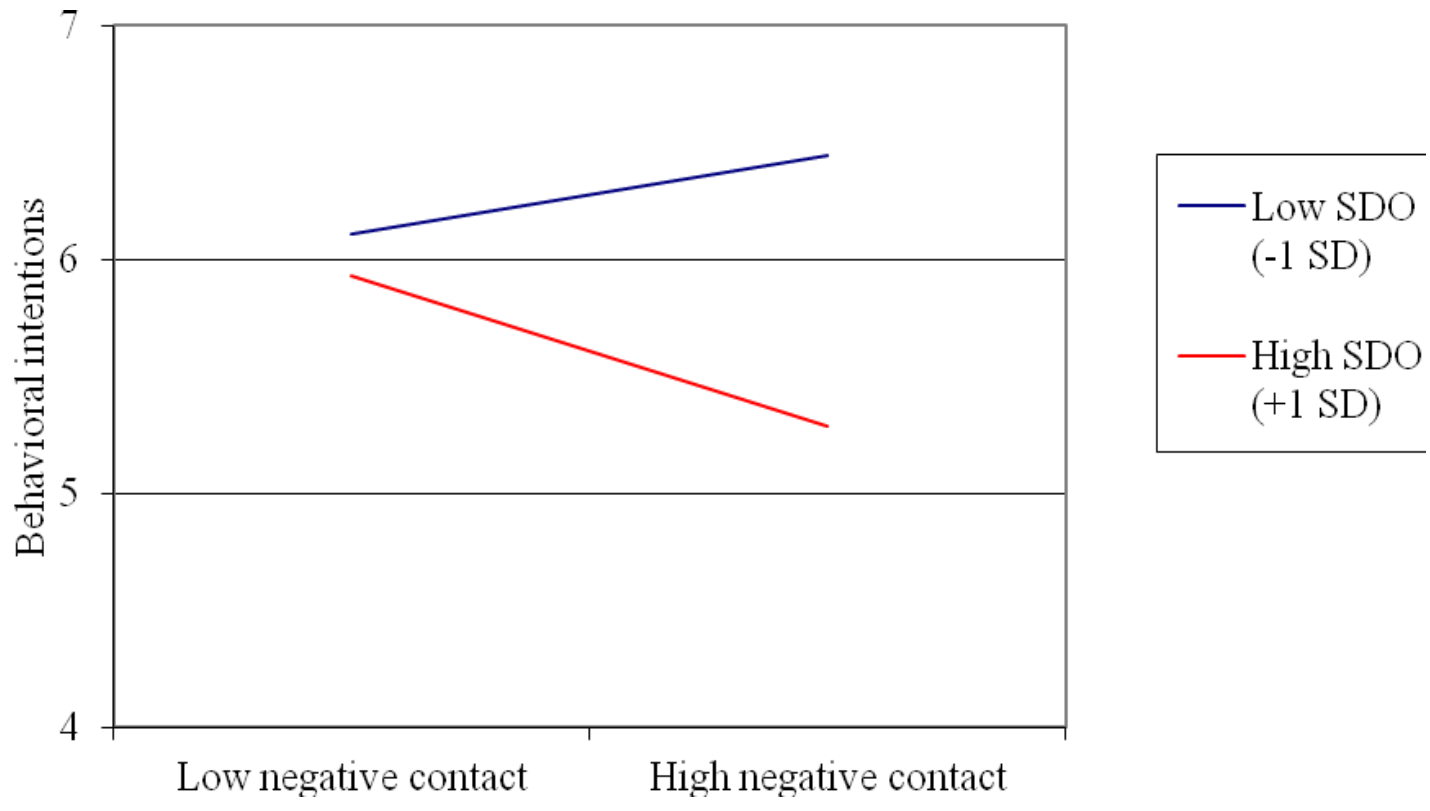

Figure 3 


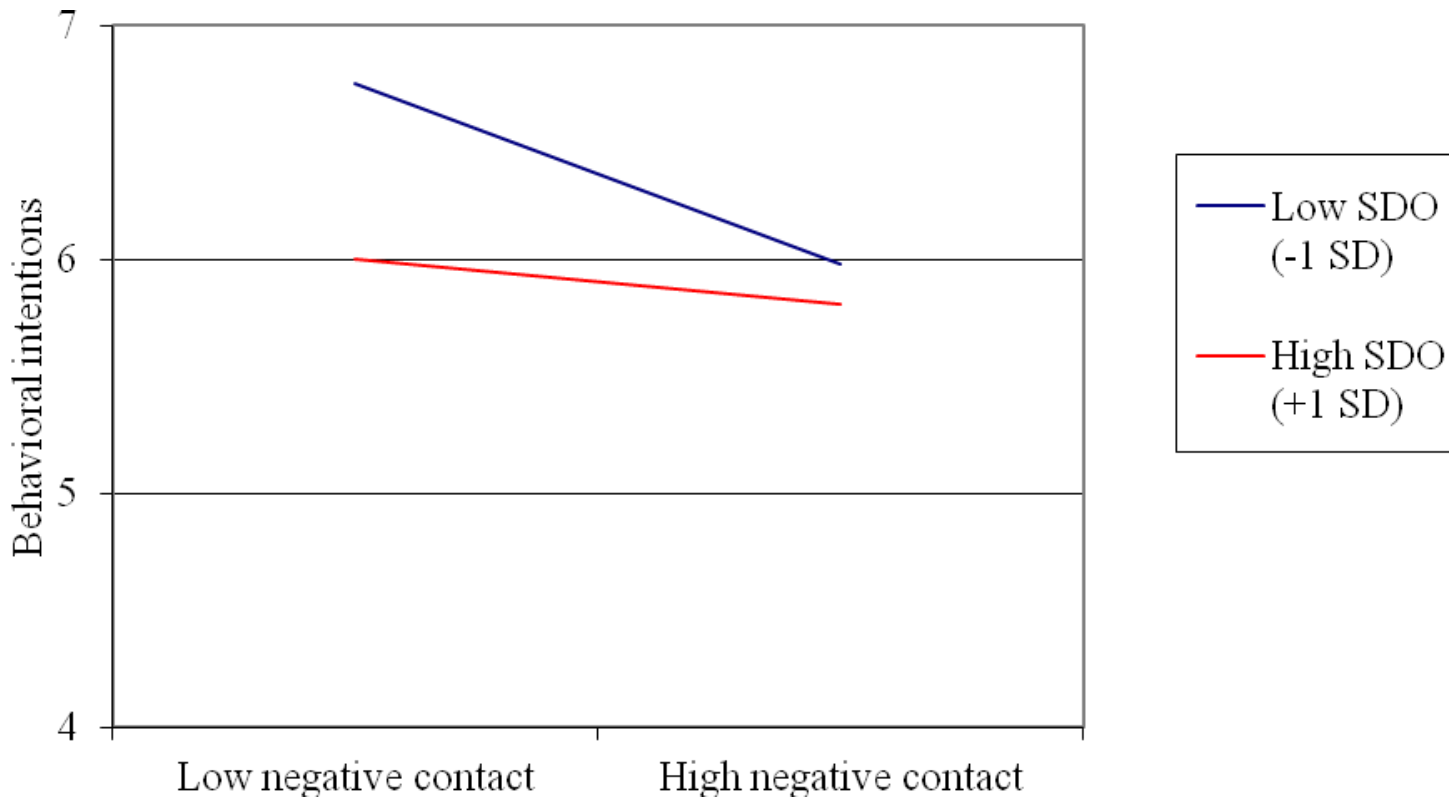

